\title{
Tsafon
}

Revue d'études juives du Nord

$76 \mid 2018$

Expressions yiddish de la nature

\section{À nos lecteurs}

\section{Tsafon}

\section{OpenEdition}

Journals

Édition électronique

URL : https://journals.openedition.org/tsafon/784

DOI : $10.4000 /$ tsafon.784

ISSN : 2609-6420

\section{Éditeur}

Association Jean-Marie Delmaire

\section{Édition imprimée}

Date de publication : 1 décembre 2018

Pagination : 5

ISSN : 1149-6630

\section{Référence électronique}

Tsafon, «À nos lecteurs », Tsafon [En ligne], 76 | 2018, mis en ligne le 30 juin 2019, consulté le 24 juin 2021. URL : http://journals.openedition.org/tsafon/784 ; DOI : https://doi.org/10.4000/tsafon.784 


\section{À NOS LECTEURS}

Deux spécialistes de la littérature yiddish, Marie SchumacherBrunhes et Michèle Tauber se sont associées pour présenter un dossier qui rassemble des études sur les « expressions yiddish de la nature ». La nature ne fut pas toujours le quotidien des juifs des villes d'Europe centrale, en revanche les habitants du shtetl évoluaient, quant à eux, dans un environnement campagnard. La nature est présente dans la littérature ancienne (Mayse bukh), le Baal Shem Tov en était proche ; elle a aussi sa place chez des auteurs plus récents (Kulbak, Zychlinsky, Heller). Enfin, Aleksander Ford décrit, dans son film Mir kumen on de 1935, un «éden bundiste » où les enfants s'ébattent, pleins de santé, « au soleil et dans la joie ». La nature s'exprime aussi en yiddish.

Plusieurs villes israéliennes honorent Lazar Zamenhof en attribuant son nom à une de leurs rues; à juste titre puisque l'inventeur de l'espéranto fut un adepte du sionisme, à l'époque des premiers pionniers, ce qui est peu connu car sa postérité s'appuie surtout sur sa trouvaille linguistique comme le rappelle Christian Lavarenne. C'est que, sceptique quant à la réussite du projet sioniste, Zamenhof s'en éloigna pour se consacrer à un autre rêve : créer une langue unissant les peuples comme l'hébreu a pu unir le peuple juif.

Gertrud Kolmar, assassinée en 1943 à Auschwitz, pressent dès 1933 le désastre qui menace les juifs d'Allemagne. Rapidement et avec clairvoyance, elle manifesta son inquiétude dans des poèmes qui contrastent avec son œuvre antérieure. Helmut Pillau précise que, malgré son arrestation et sa disparition, ses écrits, cachés par des membres de sa famille, ont pu être édités après la guerre.

Constance Pâris de Bollardière livre le commentaire d'une lettre écrite en octobre 1946 par Yankev Pat, secrétaire du Jewish Labor Committee organisme bundiste établi aux USA, et adressée à Marek Edelman, l'un des dirigeants de la révolte du ghetto de Varsovie. Au 
lendemain de la Catastrophe, le survivant de l'extermination des juifs s'interroge sur le choix de son nouveau lieu de vie. Bundiste, il n'envisage pas une émigration vers la Palestine et, finalement, il reste insensible aux arguments de Yankev Pat qui lui conseille de quitter la Pologne puisque c'est dans ce pays, devenu communiste, qu'il finit par s'établir.

C'est bien chaleureusement que Tsafon remercie Daniel et Jacqueline Mandelbaum de l'avoir autorisé à publier le souvenir du sauvetage de leurs parents sur le quai de la gare de Fives-Lille, ce 11 septembre $1942^{1}$. Le témoignage s'appuie sur les récits que Tauba et Lejbus ont racontés à leurs enfants. Leur courage et leur détermination ont eu raison de la démence nazie qui devait les assassiner, mais ils ne suffisaient pas. Encore fallait-il obtenir la complicité, pas moins courageuse et bien audacieuse, d'un cheminot : Marcel Hoffmann.

Plus qu'un hommage à Philip Roth, Maxime Decout offre aux lecteurs une courte étude sur toute l'œuvre de l'écrivain disparu cette année. Dans les « Informations », Danielle Delmaire réunit trois grandes dames rescapées de la Shoah qui ont témoigné de leur adolescence brisée dans le camp d'Auschwitz. Simone Veil, Marceline Loridan-Ivens et Ida Grinspan se sont éclipsées en 2017-2018, leurs témoignages survivront.

À toutes et à tous, bonne lecture

Tsafon

Remarque : Comme toujours, nous laissons aux auteurs le choix d'écrire le substantif « juif » avec ou sans majuscule.

\section{Communiqué :}

Nous apprenons que Jacques Ehrenfreund, professeur à l'université de Lausanne et membre de notre comité de rédaction, a été, en sa qualité de «professeur de judaïsme» (sic!) et de « ressortissant franco-israélien ", la cible de propos fleurant l'antisémitisme de la part d'un collègue, propos relayés par un journal suisse qui a dénié tout droit de réponse à Jacques Ehrenfreund. Nous assurons notre collègue de notre entier soutien.

\footnotetext{
${ }^{1}$ Sur cet épisode courageux du sauvetage, par des cheminots, de plusieurs dizaines de juifs du Nord et du Pas-de-Calais, raflés le 11 septembre 1942 Tsafon a publié : Monique Heddebaut, Sans armes face à la rafle du 11 septembre 1942 (dans la «Zone rattachée » à Bruxelles), article édité à part du n 70, automne 2015 - hiver 2016.
} 